\title{
BARRUCAND (Marianne), éd., L'Égypte fatimide. Son art et son histoire
}

Paris, Presses de l'Université de Paris-Sorbonne, 1999, 704 p. (illustr.)

\section{Christian Décobert}

\section{OpenEdition}

\section{Journals}

Édition électronique

URL : http://journals.openedition.org/assr/20844

DOI : $10.4000 /$ assr. 20844

ISSN : $1777-5825$

\section{Éditeur}

Éditions de l'EHESS

Édition imprimée

Date de publication : 1 juin 2001

Pagination : 125-126

ISBN : 2-222-96704-X

ISSN : 0335-5985

\section{Référence électronique}

Christian Décobert, "BARRUCAND (Marianne), éd., L'Égypte fatimide. Son art et son histoire », Archives de sciences sociales des religions [En ligne], 114 | avril-juin 2001, document 114.52, mis en ligne le 19 août 2009, consulté le 21 septembre 2020. URL : http://journals.openedition.org/assr/20844 ; DOI https://doi.org/10.4000/assr.20844

Ce document a été généré automatiquement le 21 septembre 2020

(C) Archives de sciences sociales des religions 


\title{
BARRUCAND (Marianne), éd., L'Égypte fatimide. Son art et son histoire
}

Paris, Presses de l'Université de Paris-Sorbonne, 1999, 704 p. (illustr.)

\author{
Christian Décobert
}

\section{RÉFÉRENCE}

BARRUCAND (Marianne), éd., L'Égypte fatimide. Son art et son histoire, Paris, Presses de l'Université de Paris-Sorbonne, 1999, 704 p. (illustr.)

1 Un important colloque, organisé par M.B., eut lieu en Sorbonne du 28 au 30 mai 1998. Son objet: l'Égypte fatimide. L'ouvrage qui en constitue les Actes est une véritable somme sur ces deux siècles (969-1170) de l'Égypte médiévale, mais aussi sur la présence des Fatimides en Afrique du Nord et au Proche-Orient, sur leurs influences en Méditerranée et sur la route des Indes.

Ce lourd ouvrage est découpé ainsi : section 1, les espaces politiques et idéologiques fatimides; section 2, les monuments et leurs inscriptions; section 3/1-2, les arts mobiliers; section $3 / 3$, les arts du livre ; section 4 , l'art funéraire ; section 5 , histoire des sciences et des loisirs ; section 6, les communautés juives et chrétiennes ; section 7 , le rayonnement des Fatimides. On le voit, l'ouvrage est très nettement orienté vers l'histoire de l'art, discipline qui est d'ailleurs dans l'orientalisme continental (français et allemand) si dominante qu'elle recouvre et oriente des champs d'études très divers. À témoin, la section 4, consacrée en principe à l'art funéraire, et qui regroupe deux contributions. L'une, d'un archéologue (R.-P. Gayraud : «La Qarâfa al-Kubrâ, dernière demeure des Fatimides ») parle de la structure, comme domaine à la fois des morts et des vivants (avec son bain, ses jardins, ses lieux de repos), d'un complexe funéraire royal. L'autre, d'un historien ( $\mathrm{T}$. Leisten: «Dynastic Tomb or Private Mausolea: Observations on the Concept of Funerary Structures of the Fâtimid and 'Abbâ-sid 
Caliphs ») travaille le concept, à la fois riche et discuté, de «monument commémoratif » en islam, à propos de tombes privées, familiales, mais qui font aussi l'objet d'une vénération publique. Quant à la section 7, sur les influences extérieures des Fatimides, elle traite sans hiérarchisation tout aussi bien des faits de diffusion de l'architecture que des routes commerciales.

Ainsi le corps de l'ouvrage est pensé comme une vaste histoire de l'art fatimide, mais où ce qui concerne les modes de pensée (section 1 ), les modes de savoir (section 5 ) et les relations interreligieuses (section 6) ont une place non négligeable et comme obligée. Pour une revue comme la nôtre, les A.S.S.R., que peut-on saisir d'un tel ouvrage?

Les califes fatimides d'Égypte étaient des chiites ismaéliens, étrangers donc à une Égypte profondément sunnite ; leur administration centrale était largement aux mains de l'élite chrétienne, et si certains gestes (du calife al-Hakim, notamment) furent de discrimination religieuse, il est acquis que les Fatimides furent globalement très tolérants envers les minoritaires. Ceci dit, il apparaît bien (J. den Heijer: «Considérations sur les communautés chrétiennes en Égypte fatimide : l'État et l'Église sous le vizirat de Badr al-Jamalî (1074-1094)») que les chrétiens avaient vécu une profonde acculturation depuis la conquête arabe et que l'Église n'était plus tant aux mains des moines que des élites urbaines, civiles, proches du pouvoir musulman: c'étaient les marchands et grands propriétaires chrétiens qui désormais devenaient évêques, qui faisaient et défaisaient les patriarches, qui protégeaient les églises et les lieux de pèlerinage. Par ailleurs, une islamisation rampante touchait les milieux minoritaires : telle pratique juive de culte de saints était à la fois directement calquée du mawlid (fête anniversaire d'un saint) musulman et se posait en réaction communautaire à l'emprise sur les lieux et les hommes (J. Kraemer : " A Jewish Cult of the Saints in Fâtimid Egypt »).

5 Pour autant, un tel ouvrage, même si, encore une fois, il est largement consacré à l'art, nous apprend beaucoup - notamment dans sa section 2, sur les monuments et les inscriptions officielles - sur le fait que c'est alors qu'un paysage musulman s'est mis en place, que c'est pendant ces deux siècles que les signes de la présence musulmane se sont multipliés, se sont popularisés et ont envahi peu à peu les villes mais aussi les campagnes. On peut certes s'interroger, et de façon très argumentée et parfaitement convaincante (O. Grabar: "Qu'est-ce que l'art fatimide?»), sur ce qui constitue réellement l'art fatimide d'Égypte, sur le fait qu'il est certainement tout autant méditerranéen que musulman ou qu'égyptien, tant ses origines sont diverses. Il reste que la constitution, en elle-même, de traits décoratifs ou architecturaux reconnaissables, stables, reproductibles, et que la diffusion de ces traits sont des phénomènes d'une importance première pour l'histoire de l'islam en Égypte mais aussi pour l'histoire des relations intercommunautaires. Désormais, était rendue visible ce qu'on pourrait appeler une culture dominante, ou plutôt une culture manifestant ainsi, par des monuments et des inscriptions, sa domination, chez les siens mais aussi auprès des non-musulmans. Un espace musulman s'instituait - ceci est, au propre, un fait d'islamisation. La spécificité de l'art de l'époque fatimide intéresse l'historien de l'art, sa fonction sociale et sa présence signifiante intéressent l'historien du religieux.

Un livre tel que celui-ci peut être lu pour ce qu'il est d'abord : un état des lieux, un état de la recherche sur une époque et un art de l'islam. Mais il peut aussi être questionné, tiré vers des terrains et des objets plus nouveaux. En ce sens, il est précieux. 